TESTING CROSS-LAGGED RELATIONSHIPS BETWEEN WORK-RELATED RUMINATION AND WELL-BEING AT WORK IN A THREE-WAVE LONGITUDINAL STUDY ACROSS

ONE AND TWO YEARS

Ulla Kinnunen $^{1}$, Taru Feldt ${ }^{2}$ \& Jessica de Bloom ${ }^{1,3}$ Faculty of Social Sciences (Psychology), Tampere University ${ }^{1}$ 33014 Tampere University, Finland e-mail: Ulla.Kinnunen@uta.fi

Department of Psychology, University of Jyväskylä P.O. Box 35, 40014 University of Jyväskylä, Finland e-mail: Taru.Feldt@jyu.fi

Faculty of Economics \& Business, University of Groningen ${ }^{3}$ P.O. Box 72, 9700 AB Groningen, The Netherlands e-mail: Jessica.De.Bloom@uta.fi

Author note

This study was supported by the Academy of Finland (grant no. 257682). Correspondence concerning this article should be addressed to Ulla Kinnunen: Ulla.Kinnunen@uta.fi 


\begin{abstract}
The aim of this three-wave longitudinal study conducted among 664 Finnish employees was to examine the cross-lagged relationships between various work-related ruminative thoughts (affective rumination, problem-solving pondering, lack of detachment from work) during off-job time and employee well-being (exhaustion, vigour). We tested normal, reversed and reciprocal temporal relationships across one and two years using structural equation modelling. The analyses lent most support to the reversed temporal relationships showing first that high exhaustion predicted low problem-solving pondering two years later and second, that high vigour predicted low affective rumination both one year and two years later. In addition, a normal temporal relationship was supported in one model indicating that high affective rumination predicted high exhaustion one year later. Thus our study suggests that affective ruminative thoughts in particular play a negative role in cross-lagged relationships. On the basis of our results occupational health interventions intended to reduce both affective work-related rumination and exhaustion, and to increase vigour at work are desirable.
\end{abstract}

Key words: detachment, exhaustion, pondering, recovery, rumination, vigour 
Testing cross-lagged relationships between work-related rumination and well-being at work in a three-wave longitudinal study across one and two years

Practitioner points:

- Affective rumination during off-job time predicted increased job exhaustion across one year. Prevent affective rumination by training employees to change ways of thinking and to create action plans on setting and completing work goals.

- Vigour predicted reduced affective work-related rumination in the long-term. Provide employees with sufficient job resources to increase their vigour at work.

- Exhaustion predicted reduced problem-solving pondering during off-job time in the long-term. Attention should be paid to ensuring that job demands are not so high that they increase exhaustion. Care should be taken to ensure that problem-solving pondering replenishes energy resources.

It has been consistently suggested that insufficient recovery from work, especially over extended periods of time, results in resource depletion and impairs employees' well-being (Cropley \& Ziljstra, 2011; Geurts \& Sonnentag, 2006; Sonnentag, Venz, \& Casper, 2017). However, longitudinal evidence on these expected long-term detrimental effects on employee well-being is scarce, as the current knowledge base mainly consists of findings from cross-sectional studies together with diary studies (see Bennett, Bakker, \& Field, 2018; Wendsche \& Lohmann-Haislah, 2017, for meta-analyses). This is an important research gap; only longitudinal research encompassing prolonged time periods can provide appropriate information about the (lagged) associations between recovery and employee well-being. Additionally, longitudinal research can help to disentangle the temporal order of the associations. That is, to test whether insufficient 
recovery has a lagged effect on poor well-being or conversely whether poor well-being has a lagged effect on insufficient recovery. A lagged effect occurs when the effect takes time to develop, and it is operationalized as the extent to which a variable at one point in time predicts another variable at a later point in time, controlling for its baseline level (Ford et al., 2014). Thus studying lagged effects is an important step forward in recovery research and has been urgently called for (e.g., Sonnentag et al., 2017). In our study we examine the lagged effects of one and two years between (in)sufficient recovery (in terms of work-related rumination) and well-being outcomes (exhaustion and vigour at work).

Effort-recovery theory (Meijman \& Mulder, 1998) suggests that people must invest mental and physical resources to deal with work-related demands. This investment results in a depletion of resources and “a need to recover” (van Veldhoven, 2008). Recovery will only occur if the depleted systems are no longer taxed during off-job time (Meijman \& Mulder, 1998). Therefore, one factor that is critical in the facilitation of adequate recovery is psychological detachment from work during time off the job. Psychological detachment refers to "an individual's sense of being away from the work situation” (Etzion, Eden, \& Lapidot, 1998, p. 579) and implies refraining from job-related activities and mentally disengaging from work during time off the job (Sonnentag \& Fritz, 2007, 2015). However, during off-job time people may ruminate, that is, think about work-related issues, demands and events (Querstret \& Cropley, 2012). Some people think about tasks they have left uncompleted, others ruminate about a problem that needs to be solved, and others' attention is mainly directed to feelings related to work problems (Cropley \& Zijlstra, 2011; Syrek \& Antoni, 2014). According to effort-recovery theory, this kind of thinking may jeopardize recovery from work. In the present study, we approach work-related rumination broadly, covering its different facets: affective rumination, problem-solving pondering, (lack of) detachment.

Our study contributes to the recovery and rumination literature in four ways. First, the longitudinal design contributes to a better understanding of the long-term relationships between 
work-related rumination and employee well-being. More specifically, we can study normal (i.e., the typical, theory-based temporal pattern explored in studies), reversed and reciprocal effects between work-related rumination and employee well-being. Second, using three measurement points with a one-year time lag we are able to test the lagged relationships across one and two years. To employ several time points in measurements is considered important when the appropriate time lag is unknown (Kelloway \& Francis, 2013; Taris \& Kompier, 2014) - as in our case. Although the appropriate length of the time lag between measurements is a crucial issue in longitudinal research (Dormann \& Griffin, 2015), we seldom know the correct underlying time lag needed to show the lagged effects. Third, we define work-related rumination broadly including affective rumination, problem-solving pondering and lack of detachment from work (Cropley \& Zijlstra, 2011). Therefore our study can show whether there are differential effects of various forms of ruminative thoughts on employee well-being. The present study examines the idea that, depending on the type of rumination, work-related rumination may not necessarily be a factor detrimental to recovery and well-being. Fourth, our study also contributes to the study of employee well-being. We examine job exhaustion and vigour at work, which are considered important outcomes from the viewpoint of recovery (Sonnentag \& Geurts, 2009), that is, indicating to what extent energy resources are available to the individual in the long term. These are also theoretically interesting outcomes, as they have been shown to be independent constructs and not only endpoints of the same energy construct (Demerouti, Moster, \& Bakker, 2010; Mäkikangas, Feldt, Kinnunen, \& Tolvanen, 2012). Besides these theoretical implications, the resulting knowledge may result in new practical implications for developing targeted occupational health interventions. For example, the results may help to specify whether interventions should be primarily targeted at certain types of work-related rumination or well-being or both of these. 


\section{Theory and Hypotheses Development}

\section{Work-Related Rumination}

Martin and Tesser (1996, p. 7) conceptualized rumination as "a class of conscious thoughts that revolve around a common instrumental theme and that recur in the absence of immediate environmental demands requiring the thoughts”. Rumination also relates to unattained goals, as unexpected (slower or faster) progress towards a goal prompts rumination (Martin \& Tesser, 1996, p. 4). Despite this fairly neutral definition, there is a tendency in the literature to conceptualize rumination as a negative process, and in fact most research focuses on repetitive thinking about negative experiences. However, rumination does not necessarily need to be a negative experience. Besides distinguishing positive and negative ruminative thoughts, Segerstrom, Stanton, Alden, and Shortridge (2003) argued that they should also be separated according to their purpose or focus (i.e., problem-solving vs. searching for meaning). Pravettoni, Cropley, Leotta and Bagnara (2007) differentiated between “repetitive” and “creative” rumination, and, more recently, Cropley and Zijlstra (2011) have differentiated between affective rumination and problem-solving pondering. In the present study we defined work-related rumination in line with Cropley and Zijlstra (2011) who have included three concepts under work-related rumination (see also Querstret \& Cropley, 2012; Zijlstra et al., 2014): affective work-related rumination, problem-solving pondering and lack of psychological detachment from work. Affective rumination is described as the experience of intrusive, pervasive and recurrent thoughts, in which attention is mainly directed to feelings related to work problems. This kind of thinking about work-related issues results in a negative emotional response (e.g., frustration, annoyance). In this affective state, psychophysiological arousal remains high, which is not conducive to the recovery process (Brosschot, Gerin, \& Thayer, 2006). Particularly in the long run, affective rumination may result in cumulative effects on well-being by chronically depleting resources over time (Firoosabadi, Uitdewilligen, \& Ziljstra, 2016; Sluiter, Frings-Dresen, van der Beek, \& Meijman, 2001). It has also 
been shown that perseverative cognition (i.e., rumination about the past and worries about the future) affects cardiovascular, autonomic and endocrine nervous system activity, suggesting a pathogenic pathway to long-term disease outcomes (see Ottaviani et al., 2016, for a meta-analysis).

In contrast, problem-solving pondering is focused on finding solutions to work-related problems. Accordingly, problem-solving pondering is defined as unemotional, prolonged thinking about solutions to particular work-related problems (Cropley \& Zijlstra, 2011). The consequences of problem-solving pondering may therefore be positive if it results in a solution. Even if the problem is not solved, pondering may lead to a specific plan for dealing with the task, which also promotes recovery as then the job task is no longer present in mind (Syrek, Weigelt, Peifer, \& Antoni, 2017). Firoosabadi et al. (2016) have therefore argued that problem-solving pondering may reduce cumulative effects on well-being by producing psychological resources over time.

Psychological detachment from work refers to the subjective experience of leaving work behind, to "switching off” and to forgetting work during non-work time (Sonnentag \& Fritz, 2007). Thus it means not thinking about one’s job and also includes detaching from positive work events and thoughts, such as reflecting positively about one’s job during non-work time. Successful psychological detachment from work during off-job time has been shown to be a powerful recovery experience promoting recovery (see Sonnentag \& Fritz, 2015; Sonnentag et al., 2017; Wendsche \& Lohmann-Haislah, 2017, for reviews). However, evidence on its longitudinal effects on well-being is this far scarce (see Sianoja, Kinnunen, Mäkikangas, \& Tolvanen, 2018; Sonnentag, Binnewies, \& Mojza, 2010, for exceptions).

From these definitions of the three concepts, we may conclude that affective rumination and pondering imply lack of detachment. Nevertheless, lack of detachment may refer to the appearance of any kind of work-related thoughts (repetitive or not, negative or positive, problem-focused or not). Earlier studies have shown that although these three types of work-related ruminative thoughts are separate concepts, they correlate with each other. According to Sonnentag and Fritz (2015), 
poor detachment relates to rumination (both affective rumination and problem-solving pondering) but is not an identical concept (correlations range between .40 and .50). Affective rumination and problem-solving pondering have shown correlations of a level similar to that of poor detachment (Firoozabadi et al., 2016; Hamesch, Cropley, \& Lang, 2014; Querstret \& Cropley, 2012). Thus these three concepts seem to capture different aspects of work-related rumination.

\section{Absence of Exhaustion and Vigour as Resources}

As discussed earlier, work-related rumination is expected to have effects on recovery, and, depending on the nature of the thoughts, the effects may be either negative or positive. In the present study we examined both exhaustion and vigour as outcomes of work-related rumination during off-job time. On the basis of conservation of resources (COR) theory, we define them both as valued energy resources (Hobfoll, 2001). Internal resources, such as energy and positive mood, are the most important resources in the context of recovery from work (Sonnentag \& Fritz, 2007).

We focused on job exhaustion, which is the core symptom of burnout (Maslach, Schaufeli, \& Leiter, 2001), and vigour at work, which is the core component of work engagement (Shirom, 2010). Job exhaustion refers to feelings of strain, tiredness and fatigue due to prolonged involvement in an over-demanding work situation depleting an individual's overall energy (Maslach et al., 2001). Vigour refers to high levels of energy and mental resilience while working, the willingness to invest effort in one's work, and persevering in the face of difficulties (Schaufeli, Salanova, González-Romá, \& Bakker, 2002). Both of these can be considered long-term outcomes, as job exhaustion, as part of the larger burnout concept, is seen as a chronic state which is not relieved by daily or weekly rest (Maslach et al., 2001) and vigour at work, as part of the larger concept of work engagement (Schaufeli et al., 2002), refers to persistent positive mood rather than a momentary state. 


\section{Hypotheses Development}

We base our hypotheses regarding normal, reversed and reciprocal effects between workrelated rumination and employee well-being on effort-recovery theory (Meijman \& Mulder, 1998) and COR theory (Hobfoll, 2001). Effort-recovery theory emphasizes that resources invested in work are best replenished during off-job time by refraining from work demands. COR theory proposes that when an individual experiences stress resources are threatened or lost. For recovery to take place, new internal resources (e.g., energy) must be gained and threatened or lost resources must be restored (Sonnentag \& Fritz, 2007). Both theories emphasize resource depletion and replenishment and, based on both theories, energy can be considered the most relevant resource for recovery. From COR theory we utilize the concepts of resource loss (depletion) and gain (replenishment) and their cycles/spirals. These cycles suggest that individuals with more resources are better equipped for resource gains and that individuals with fewer resources are more likely to experience resource losses.

In our study we test the hypotheses over one and two years. As the appropriate time lag to examine long-term recovery processes is unknown, it is important to study several time points to detect potential lagged effects (Dormann \& Griffin, 2015; Kelloway \& Francis, 2013; Taris \& Kompier, 2014). Based on the current knowledge, we have no theoretical reasons to expect that the effects would be different over one year or two years. These two time lags were chosen as there are earlier studies showing that one year may be an appropriate time lag to reveal the lagged effects (Firoozabadi et al., 2016; Sianoja et al., 2018; Sonnentag et al., 2010). In addition, one-year time lags appear to be most common and useful in longitudinal studies investigating the long-term job stressors-strain relationship (see Ford et al., 2014, for a review). Job stressors are closely related to work-related rumination (Kinnunen et al., 2017; Syrek et al., 2017). However, as not all studies using a one-year time lag have revealed lagged effects (e.g., Firoozabadi et al., 2016; Kinnunen \& 
Feldt, 2013), we expanded the time lag to two years. As we were interested in long-term effects, we considered a longer time period more appropriate than a shorter one.

Normal lagged effects of affective rumination on well-being. Affective rumination after work leads to sustained activation because there are negative outcome expectancies for attaining work goals (Martin \& Tesser, 1996). In addition, ruminating about the negative aspects of work is associated with increased negative affect, which also maintains prolonged activation and influences well-being negatively in the long run (Finch, Baranik, Liu, \& West, 2012). As a result, individuals' resources are drained during recovery time; that is, exhaustion exacerbates and vigour diminishes. So far this resource loss has only been empirically examined in one longitudinal study: Firoozabadi et al. (2016) showed that affective rumination was a significant predictor of increase in exhaustion over one year. In addition, in a cross-sectional study by Querstret and Cropley (2012) affective rumination was significantly associated with increased work-related fatigue. It has also been shown that those scoring high in affective rumination showed least work engagement, of which vigour is a part, over a two-year period (Kinnunen et al., 2017). Based on this evidence, we hypothesize:

H1a. Affective rumination is positively related to job exhaustion across one and two years.

H2a. Affective rumination is negatively related to vigour across one and two years.

Normal lagged effects of problem-solving pondering on well-being. Although problemsolving pondering during recovery time draws on an individual's cognitive resources, pondering about interesting work-related issues and finding solutions to them may serve as a recovery experience (Bennett, Gabriel, Calderwood, Dahling, \& Trougakos, 2016) and cause positive affect (Seo, Barrett, \& Bartunek, 2004). Especially in the long run, according to the broaden-and-build theory of positive emotions (Fredrickson, 1998), momentary experiences of positive emotions can trigger upward spirals toward well-being over time by building psychological resources (Fredrickson \& Joiner, 2002). In the cross-sectional study by Querstret and Cropley (2012) problem-solving pondering was associated with reduced fatigue. In two other studies employees 
high in pondering exhibited the highest level of work engagement (Bennett et al., 2016; Kinnunen et al., 2017), of which vigour is a part (Schaufeli et al., 2002). In the latter study, high engagement among pondering employees was observed across two years. Based on these considerations, we hypothesize:

H3a. Problem-solving pondering is negatively related to job exhaustion across one and two years.

H4a. Problem-solving pondering is positively related to vigour across one and two years.

Normal lagged effects of lack of detachment from work on well-being. According to Sonnentag and Fritz (2015), detachment from work can stop acute load reactions (such as fatigue) from accumulating and prevent an increase in chronic strain reactions over time. Without detachment the energy loss cycle continues as resources are not replenished during off-job time, suggesting an increase in exhaustion and a decrease in vigour in the long term. Two recent metaanalyses (Bennett et al., 2018; Wendsche \& Lohmann-Haislah, 2017) and one review (Sonnentag \& Fritz, 2015) showed that detachment is systematically associated with less exhaustion and more vigour and the relationship may be stronger with fatigue (including exhaustion) than vigour. To date two longitudinal studies have found that lack of psychological detachment from work predicted an increase in job exhaustion over the course of one year (Sianoja et al., 2018; Sonnentag et al., 2010). We propose the following hypotheses:

H5a. Lack of psychological detachment is positively related to job exhaustion across one and two years.

H6a. Lack of psychological detachment is negatively related to vigour across one and two years.

Reversed lagged effects of well-being on affective rumination. High exhaustion combined with low vigour means that resources to attain work goals are reduced. This may in turn trigger affective rumination in the long-term as the rate of progress toward goals is slower than expected 
(Martin \& Tesser, 1996, p. 4). Conversely, when energy resources are high (high levels of vigour, in particular), work goals are more easily achieved and affective rumination is avoided. High exhaustion entails poorer cognitive functioning, such as memory and attention deficits, assessed by self-ratings, peer-ratings and neuropsychological testing (Feuerhahn, Stamov-Roßnagel, Wolfram, Bellingrath, \& Kudielka, 2013) due to the preoccupation of the mind with worrying thoughts. Poorer cognitive functioning due to poor well-being may also be an important factor explaining the link between well-being and job performance (Vuori et al., 2014). Performance deficits may increase over time because exhausted employees will be less and less able to invest extra effort in order to compensate for these deficits. As a result, exhausted employees may increasingly ruminate about their work or try to complete work-related tasks outside working hours. As far as we know, no longitudinal empirical evidence on these reversed relationships has so far been presented. Based on theoretical considerations, we hypothesize:

H1b. Job exhaustion is positively related to affective rumination across one and two years.

$H 2 b$. Vigour is negatively related to affective rumination across one and two years.

Reversed lagged effects of well-being on problem-solving pondering. We also expect that high levels of exhaustion may lead to a decrease in problem-solving pondering and high levels of vigour may lead to an increase in problem-solving pondering across time. Exhaustion implies fewer energy resources to achieve work goals, and therefore less goal-directing problem-solving pondering, whereas vigorous employees may be energized to engage in problem-solving pondering during their free time. Employees with burnout also often report reduced problem-solving and learning abilities (Maslach et al., 2001; Schaufeli \& Enzmann, 1998). In addition, exhausted employees may have difficulties in focusing their thoughts on work goals due to deficits in selfcontrol, for example, in attention direction (Van Der Linden, Keijsers, Eling, \& van Schaijk, 2005), which decreases problem-solving pondering in the long-term. Vigour - as well as work engagement - is maintained through the achievement of work goals (Leiter \& Bakker, 2010), which further 
supports the positive link between vigour and pondering in the long term. However, there is as yet no longitudinal evidence on potential reversed lagged effects. Based again on theoretical considerations, we hypothesize:

$H 3 b$. Job exhaustion is negatively related to problem-solving pondering across one and two years.

$H 4 b$. Vigour is positively related to problem-solving pondering across one and two years.

Reversed lagged effects of well-being on lack of detachment from work. Sonnentag and Fritz (2015) argue that employees higher in burnout may have a harder time detaching from work. The reason for that may relate to reduced self-regulative capacity that would be needed to refrain from thinking about work-related matters when it is not necessary (Muraven \& Baumeister, 2000). The study by Sonnentag, Arbeus, Mahn and Fritz (2014) found that exhaustion predicts a decrease in psychological detachment from work over the course of four weeks. This decrease was particularly marked among employees working under time pressure and those who did not engage in pleasurable leisure experiences. Thus these findings suggest that exhausted employees find detachment from work increasingly difficult to achieve and may therefore suffer from insufficient recovery - although they are the ones who need it most. For example, initially exhausted employees may try to counteract their exhaustion by investing extra effort, which in turn further depletes their energy resources and exacerbates the negative consequences in the long-term. Conversely, vigorous employees have enough energy and therefore self-control to detach from work and maintain their vigour in the long term. We propose the following hypotheses:

$H 5 b$. Job exhaustion is positively related to lack of psychological detachment across one and two years.

$H 6 b$. Vigour is negatively related to lack of psychological detachment across one and two years. 


\section{Reciprocal lagged effects between rumination and well-being. Based on COR theory}

(Hobfoll, 2001), we also speculate that both types of lagged effects (normal and reversed) are simultaneously valid. In line with the principle of resource loss and gain cycles, affective rumination may trigger an energy depletion process (i.e., increase exhaustion and reduce vigour), which may, in turn, increase rumination. Problem-solving pondering may serve as a recovery experience promoting recovery (Bennett et al., 2016), that is, reduce exhaustion and increase vigour, and therefore also fuel further problem-solving pondering. Lack of detachment from work does not help to replenish energy resources (i.e., reduce exhaustion and increase vigour), which makes it more difficult to further detach from work (Sonnentag \& Fritz, 2015). As far as we know, these reciprocal effects have not been examined. Based on theoretical considerations, we hypothesize:

H1c. Affective rumination is positively related to job exhaustion and simultaneously job exhaustion is positively related to affective rumination across one and two years.

$H 2 c$. Affective rumination is negatively related to vigour and simultaneously vigour is negatively related to affective rumination across one and two years.

H3c. Problem-solving pondering is negatively related to job exhaustion and simultaneously job exhaustion is negatively related to problem-solving pondering across one and two years. H4c. Problem-solving pondering is positively related to vigour and simultaneously vigour is positively related to problem-solving pondering across one and two years.

H5c. Lack of detachment is positively related to job exhaustion and simultaneously job exhaustion is positively related to lack of detachment across one and two years.

H6c. Lack of detachment is negatively related to vigour and simultaneously vigour is negatively related to lack of detachment across one and two years. 


\section{Method}

\section{Participants and Procedure}

The participants came from 11 Finnish organizations in different sectors (e.g., education, information technology and media). By sampling different organizations, we wanted to include employees from a variety of different jobs. Participants were informed about the study goals and assured that their responses would be treated confidentially and that participation was voluntary.

The questionnaire data were collected in three waves using electronic questionnaires (see Kinnunen et al., 2017). First, in spring 2013 (Time 1), of the employees contacted $(N=3,593)$, 1,347 returned the completed questionnaire after two reminders, yielding a response rate of 36\%. Second, in spring 2014 (Time 2) those employees who responded in 2013 and who were still employed by the same organizations $(N=1,192)$ were contacted. Of these, 841 employees returned the completed questionnaire, yielding a response rate of 71\%. Third, in spring 2015 (Time 3) those who responded in 2013 and 2014, and who were still employed by the same organizations $(N=$ 799) were contacted. Of these, 664 employees responded, yielding a response rate of $83 \%$. Thus the three-wave questionnaire data included 664 participants.

At Time 1 of this long-term sample $(N=664), 58 \%$ were women. The participants' average age was 47.5 years (range 23-66, $S D=9.9$ ). Of the sample, 38\% held an academic degree (master's level or higher), 26\% had a polytechnic degree, and the rest (36\%) had a vocational school qualification or less. The majority had a permanent job (91\%), worked full-time (97\%) and worked a regular day shift (90\%). Average hours worked weekly were $39(S D=5.9)$. Of the participants, $54.5 \%$ worked in the public sector, and the rest (45.5\%) worked in the private sector (see anonymous, for a more detailed description).

\section{Sample Attrition}

In analysing sample attrition, we compared the characteristics of the participants of the longterm sample with the dropouts (non-respondents either at T2 or at T3). The results indicated that the 
participants more often had a permanent employment contract (91\% vs. 80\%, $p<.001)$, worked more often on a regular day shift ( $90 \%$ vs. $85 \%, p<.05)$ and were older (47.5 vs. 46.2 years, $p<$ .05) than the dropouts. The attrition analysis for the main study variables showed that the dropouts engaged more often in affective rumination (2.58 vs. 2.43, $p<.01)$, and reported higher levels of exhaustion (2.06 vs. 1.86, $p<.05)$ and lower levels of vigour (4.42 vs. $4.58, p<.05)$ than participants in the longitudinal sample.

\section{Measures}

This study was part of a larger project on recovery from work stress. Therefore the measures for each construct had to be short. We chose items known from earlier studies to have the highest loadings on each construct. All main constructs were measured three times (T1-T3).

Work-related rumination was measured as follows: Affective rumination ("I become tense when I think about work-related issues in my free time”, "I am irritated by work issues when not at work”, "I am annoyed by thinking about work-related issues when not at work”) and problemsolving pondering ("I find solutions to work-related problems in my free time”, "I find that thinking about work during my free time helps me to be creative”, "I think about tasks that need to be done at work the next day”) were each assessed with three items from the Work-Related Rumination Questionnaire (Cropley, Michalianou, Pravettoni, \& Millward, 2012). The response scale ranged from 1 (very seldom or never) to 5 (very often or always). Psychological detachment from work was measured using three items from the Recovery Experience Questionnaire (Sonnentag \& Fritz, 2007), which has been validated in Finland (Kinnunen et al., 2011). Participants were asked to respond to the items with respect to their off-job time ("I forget about work”, “I don’t think about work at all”, “I distance myself from my work”) using a scale ranging from 1 (totally disagree) to 5 (totally agree). These rumination concepts have been shown to be separate in factor analyses (Vahle-Hinz, Mauno, De Bloom, \& Kinnunen, 2017; Querstret \& Cropley, 2012) (see also Table 1, for correlations). 
Job exhaustion was measured with the job exhaustion scale (5 items, e.g., "I feel emotionally drained from my work”) from the Maslach Burnout Inventory - General Survey (Maslach, Jackson, \& Leiter, 1996), which has been validated in Finland (Kalimo, Hakanen, \& Toppinen-Tanner, 2006). Vigour at work was measured by the shortened 3-item scale of vigour (e.g., “At my work, I feel bursting with energy”) from the Utrecht Work Engagement Scale (Schaufeli, Bakker, \& Salanova, 2006), of which the construct validity has been found to be good in Finnish occupational samples (Seppälä et al., 2009). The response scale ranged from 0 (never) to 6 (every day) for both measures.

Regarding control variables, we focused on one job demand, that is, time pressure (too much work) at T1, because it reportedly most often plays a role in work-related rumination (Berset, Elfering, Luthy, Luthi, \& Semmer, 2011; Syrek \& Antoni, 2014; Syrek et al., 2017). Time pressure was measured with three items (“How often does your job require you to work very fast?”, "How often does your job leave you with little time to get things done?”, “How often does your job require you to work under time pressure?”) from the Quantitative Workload Inventory (Spector \& Jex, 1998). The items were rated on a scale from 1 (very seldom or never) to 5 (very often or always).

\section{Statistical Analyses}

The hypotheses of the present study were tested within the structural equation modelling (SEM) framework using the Mplus 8 programme (Muthen \& Muthen, 1998-2012). Robust maximum likelihood (MLR) was used as the method of estimation as not all variables followed a normal distribution. Missing values were processed with the general missing type procedure (i.e., models were estimated utilizing all the data available without imputing) available in the Mplus program. Latent variables constructed by multiple observed items were chosen as they offer potential advantages enabling measurement errors to be taken into account. 
We analysed the cross-lagged effects separately based on three (T1-T2-T3) and two measurement points (T1-T3) for each rumination construct and outcome. The first analysis covers the one-year cross-lagged effects and the second analysis the two-year effects. The analytical procedure included three major phases. In the first phase, a freely estimated stability model (M0) and a stability model with invariant factor loadings across time (M1) based on the latent constructs were tested. In these models, all autocovariances between the same observed variables (i.e., items) across time were allowed to correlate. The latter model (M1) was then compared with the former model (M0) using the Satorra-Bentler scaled chi-square difference test (Satorra \& Bentler, 2001) in order to establish the structural invariance of the latent variables across time. If chi-square difference test provides a non-significant loss-of-fit for MI compared to M0, then MI is supported. Demonstration of the structural invariance of the latent variables across time allows the further investigation of the longitudinal effects (i.e., cross-lagged associations between the constructs) as then the observed effects are not due to structural change in the latent constructs over time.

In the second phase, the three different (normal, reversed, and reciprocal) effect models were tested, that is, the relationships included in each model, were added separately into the stability model described above. In the normal effect models (M2) each work-related rumination construct predicted either exhaustion or vigour at the later measurement point. In the reversed effect models (M3) the relationships were the opposite: well-being variables predicted each work-related rumination construct. The reciprocal models (M4) included the relationships in both the normal and the reversed effect models. After that, the three effect models were compared to the stability model using the Satorra-Bentler scaled chi-square difference test (Satorra \& Bentler, 2001). When an effect model yields a significant improvement in the model fit compared to the stability model, the effect model is supported. If several effect models showed an improvement, they were then compared with each other using the same procedure. In the third phase, the models showing significant cross-lagged effects were adjusted for time pressure at T1 as an observed mean scale. 


\section{Results}

\section{Descriptive Results}

Means, standard deviations, Cronbach’s alphas and correlations between the study variables are presented in Table 1. Mean level changes between T1 and T3 were found for problem-solving pondering $(p=.001)$ and vigour $(p<.001)$. The level of vigour was higher at T1 than at T2 and T3, and pondering was at a higher level at $\mathrm{T} 3$ than at $\mathrm{T} 1$ and $\mathrm{T} 2$. There were significant correlations in both directions, for example, between affective rumination at T1 and job exhaustion at T2 and, conversely, between job exhaustion at $\mathrm{T} 1$ and affective rumination at $\mathrm{T} 2(r=.48$ and .45 respectively). All the variables also showed moderate rank-order stability over time ( $r=.56-.72)$.

\section{Testing the Hypotheses}

Table 2 reports the SEM models tested for job exhaustion, that is, hypotheses 1, 3 and 5 were tested. As can be seen, the structure of the stability models including latent study constructs (affective rumination, problem-solving pondering, detachment and exhaustion) turned out to be invariant across time based on the models with three (T1-T2-T3) and two measurement points (T1T3). That is, the loss of fit of the constrained models (M1, factor loadings set to be invariant across time) was non-significant compared to the freely estimated stability models (M0, factor loadings allowed to vary across time). Thus the stability models with significant and time-invariant factor loadings and a good data fit (all fit indices acceptable) served as our baseline models to which cross-lagged models were statistically compared.

The results in Table 2 indicate that $\mathrm{H} 1 \mathrm{a}$, in which affective rumination was expected to predict later exhaustion, received support. For the various cross-lagged relationships across T1-T2-T3 the normal effect model (M2) showed a better fit with the data than the baseline stability model (M1) and so did the reversed (M3) and reciprocal model (M4). The comparison of the two best fitting models showed that the reciprocal model (M4) did not show improvement in model fit compared to the normal effect model (M2). Thus the normal effect model was the best fitting model. After 
controlling for time pressure at T1 by allowing it to predict both affective rumination and exhaustion at T1 the cross-lagged effects of the normal effect model remained significant and the model fitted the data well: $\chi^{2}(261)=902.33, p<.001$, RMSEA $=0.06$, SRMR $=0.04$, TLI $=0.94$, $\mathrm{CFI}=0.95$. As seen in Figure 1a, in which time pressure was controlled for in the model, both latent constructs, particularly affective rumination, showed relatively high stability over time. High affective rumination at $\mathrm{T} 1$ was found to predict high job exhaustion one year later at $\mathrm{T} 2$ and the same predictive association was also found between T2 and T3. Thus H1a received support across one year, but not across two years. This simultaneously implies that H1b expecting the reversed link from exhaustion to later affective rumination and H1c expecting the reciprocal links did not gain support.

The models testing the various relationships between problem-solving pondering and exhaustion (H3a, H3b and H3c) revealed that H3b, in which exhaustion was expected to predict later lower pondering, received support. For the different cross-lagged relationships across T1-T3 both the reversed (M3) and reciprocal (M4) models improved the model fit compared to the stability model (M1) (see Table 2). When these two models were compared it turned out that the reciprocal model (M4) did not improve the model fit compared to the reversed model (M3). Finally, the reversed model was adjusted for time pressure at $\mathrm{T} 1\left(\chi^{2}(111)=505.46, p<.001\right.$, RMSEA $=$ $0.07, \mathrm{SRMR}=0.08, \mathrm{TLI}=0.93, \mathrm{CFI}=0.94)$ and the results indicated that the reversed cross-lagged effect remained significant. In this final model, shown in Figure 1b, high exhaustion at T1 predicted low problem-solving pondering two years later at T3, thereby lending support to H3b across two years, but not across one year.

None of the different cross-lagged models concerning the relationships between lack of detachment and exhaustion improved the model fit compared with the stability model (see Table 2). 
Thus hypotheses H5a expecting normal, H5b expecting reversed and H5c expecting reciprocal relationships did not gain support.

Table 3 reports the SEM models tested for vigour at work, that is, hypotheses 2, 4 and 6 were tested. Again, we can see that, with one exception, the stability models with time-invariant factor loadings (M1) fitted better with the data than the freely estimated stability models (M0). This exception concerned the model consisting of detachment and vigour across T1-T3: the invariant stability model slightly weakened the model fit as compared to the freely estimated model (at the level of $p<.05)$.

The results in Table 3 indicate that of the different cross-lagged models concerning the relationship between affective rumination and vigour (H2a, H2b and H2c), H2b, in which vigour was expected to predict later low affective rumination, received support. For the various crosslagged relationships across T1-T2-T3, both reversed (M3) and reciprocal (M4) models improved the model fit compared to the baseline stability model (M1). When these two best models were compared, the reciprocal model (M4) did not show improvement compared to the reversed model (M3). Therefore the reversed model was the best model. The reversed model was adjusted for time pressure at $\mathrm{T} 1\left(\chi^{2}(138)=444.15, p<.001, \mathrm{RMSEA}=0.06, \mathrm{SRMR}=0.07, \mathrm{TLI}=0.95, \mathrm{CFI}=\right.$ 0.96), which did not change the significance of the cross-lagged effects. In this final model, shown in Figure 2a, high vigour at work at T1 was found to predict low affective rumination one year later at T2. However, the same predictive association did not reach the significance level between T2 and T3 $(\beta=-.06, p=.08)$. Across T1-T3, these same models outperformed the stability model. Again, the reversed model (M3) turned out to be the best model, which did not change after adjusting for time pressure at $\mathrm{T} 1\left(\chi^{2}(57)=145.79, p<.001, \mathrm{RMSEA}=0.05, \mathrm{SRMR}=0.05, \mathrm{TLI}=0.97, \mathrm{CFI}=\right.$ 0.98). As shown in Figure 2b, high vigour at $\mathrm{T} 1$ predicted low affective rumination also two years 
later at T3. Thus H2b received support across one year and two years and correspondingly H2a, expecting normal and H2c expecting reciprocal relationships, did not gain support.

None of the different cross-lagged models concerning the relationship between pondering and vigour (H4a, H4b and H4c) and between lack of detachment and vigour (H6a, H6b, H6c) improved the model fit compared with the stability model (see Table 3). Thus none of these hypotheses expecting normal (H4a, H6a), reversed (H4b, H6b) or reciprocal $(\mathrm{H} 4 \mathrm{c}, \mathrm{H} 6 \mathrm{c})$ relationships between these constructs were supported. The results of the hypotheses testing are summarized in Table 1 in Appendix.

\section{Discussion}

Our aim was to test the different cross-lagged relationships - normal, reversed and reciprocal - between various types of work-related ruminative thoughts and two well-being outcomes indicating resource depletion and replenishment (i.e., exhaustion and vigour). Thus we wanted to take a step forward in recovery and rumination research in establishing the temporal order between rumination and well-being across one and two years. Of the various interpretations of the relationships, reversed effects gained most support, indicating that level of energy was important in determining type of ruminative thoughts.

\section{Theoretical Contributions}

Our study advanced the theoretical understanding of the lagged relationships between different work-related ruminative thoughts and well-being outcomes in the long term. First, our study contributes to a better understanding of the relationships by showing that the effects may run in both directions, and not only from rumination to well-being, as is often theoretically expected. This implies that the theories of recovery may be too simple or at least recovery processes have been studied too narrowly.

The reversed relationship from high vigour to low affective rumination especially gained longitudinal support across one, T1-T2, and two years, T1-T3. Between T2 and T3 the effect was 
marginally significant. This result obtained may be interpreted to support the view of rumination as a work-goal related concept (Martin \& Tesser, 1996, p. 4): when energy resources are high in terms of high levels of vigour, progress toward goals is expected and the goals are likely met.

Consequently, affective rumination is avoided in the long term. Those who are full of energy are also better in control to reduce ruminative thinking and this way disconnect from work (Sonnentag et al., 2014). The evidence is quite convincing as the long-term effects are found in both time lags.

Also, exhaustion played a role in predicting less problem-solving pondering across two years. This resource loss also supports the view that rumination relates to progress in attaining work goals. Exhaustion means less energy resources to achieve work goals, and therefore less goal-directed problem-solving pondering. Engaging in problem-solving pondering requires energy. The result is also in line with the findings reporting reduced problem-solving and learning abilities among employees with burnout symptoms (Maslach et al., 2001; Schaufeli \& Enzmann, 1998). This suggests that exhausted employees may not have enough mental energy to engage in problemsolving pondering during off-job time to attain their work goals. Our result moreover lends support to the findings showing that exhausted employees have difficulties in focusing their thoughts on the work goals due to self-control deficits in attention direction (Feuerhahn et al., 2013; Van Der Linden et al., 2005). It is probable that over time exhausted employees will become less and less able to invest extra effort in order to compensate for their deficits, which gradually results in a decrease in pondering. The normal effect concerning the link from problem-solving pondering to exhaustion was not supported, which is consistent with the findings of the study by Firoozabadi et al. (2016).

The resource loss from affective rumination to later exhaustion was the only relationship following normal effect model. Thus it seems that affective rumination after work leads to sustained activation (Ottaviani et al., 2016), for example, due to negative outcome expectancies regarding attaining work goals (Martin \& Tesser, 1996) and negative affect (Cropley \& Zijlstra, 2011), both 
of which influence well-being negatively in the long run. As a result, individuals' energy resources are drained during recovery time, limiting recovery during off-job time (Sonnentag et al., 2010). Our finding was similar as in the study by Firoozabadi et al. (2016) in which affective rumination was a significant predictor of increase in exhaustion over one year.

The second contribution of our study relates to the time lags used. By employing two time lags in our study we could demonstrate that the timeframes matter in examining long-term recovery processes. In particular, high exhaustion had a lagged effect on problem-solving pondering only across two years. This suggests that exhausted employees cannot invest compensatory effort in their work over long periods of time, which culminates in a decrease in problem-solving pondering during off-job time. A one-year time lag was crucial in the normal lagged effect from affective rumination to exhaustion, but in this case a two-year perspective was also meaningful as the lagged effect was seen through T1-T2-T3. Although our results provided some support for the use of both time lags, most often the lagged effects were not detected. This suggests that shorter time lags (e.g., 3-6 months) could be more optimal to show the expected cross-lagged effects (Dormann \& Griffin, 2015).

Third, defining work-related rumination broadly, we could show that only affective rumination, but neither pondering nor lack of detachment, was detrimental to well-being (increasing exhaustion) in the long term. Most strikingly, the findings did not support the role of psychological detachment in the context of employee well-being. Its important role as a recovery experience has been shown especially in cross-sectional and diary studies (Bennett et al., 2018; Sonnentag \& Fritz, 2015; Wendsche \& Lohmann-Haislah, 2017) and in two longitudinal studies in which poor detachment predicted exhaustion over one year (Sianoja et al., 2018; Sonnentag et al., 2010). Still in another study high exhaustion predicted poor detachment four weeks later (Sonnentag et al., 2014) but not vice versa. Nevertheless, there is also one study in which neither normal nor reversed 
relationships were found across one year (Kinnunen \& Feldt, 2013). Thus the longitudinal evidence is still inconclusive.

The null findings regarding detachment may relate to the fact that detachment from work includes not only detaching from negative but also from positive work-related thoughts. Therefore, the positive well-being effects found in relation to positive work reflection during off-job time (e.g., Sonnentag \& Grant, 2012) may counteract the negative effects, and result in null findings. The different types of analyses (regression analysis, latent change score models, cross-lagged analysis) employed in these earlier studies may also play a role. From a more theoretical perspective, it may be that the positive effects of psychological detachment are best realized after experiencing high stress, that is, when there is a need to recover (Sonnentag et al., 2017). In our study we were not able to take stress levels into account. Nevertheless, the inconsistent longitudinal results suggest that further studies are needed using different time lags. We recommend shorter time lags on the basis of what Dormann and Griffin (2015) recommended concerning optimal time lags in panel studies of psychological processes.

Another relationship which was not supported in either direction was that between problemsolving pondering and vigour. Problem-solving pondering did not increase vigour, nor did vigour increase problem-solving pondering. Earlier studies have suggested that pondering may be a recovery experience promoting work engagement (Bennett et al., 2016; Kinnunen et al., 2017). However, it seems that its effects are also counterproductive. When looking in more detail at the study results by Bennett and colleagues (2016), we learn that, despite high work engagement, pondering employees also had a higher exhaustion level compared to other recovery experience profiles. Therefore pondering also depletes resources to some extent, and not only replenish them. In our study pondering had slightly positive correlations with both vigour and exhaustion. It may also be that a shorter time lag would have been needed to detect lagged effects. In sum, future 
research is needed to investigate the circumstances under which problem-solving pondering and detachment facilitate (or pondering conversely impedes) the recovery process during nonwork time.

Fourth, our study also contributes to the study of employee well-being, suggesting different relationships between vigour and exhaustion. Vigour was crucial to less affective rumination, whereas exhaustion was crucial to less problem-solving pondering. These differential results support the view that vigour and exhaustion reflect independent constructs (and not mere opposite sides of the same coin), and that both should be examined (Demerouti et al., 2010; Mäkikangas et al., 2012).

\section{Practical Implications}

Based on our results, occupational health interventions intended to decrease affective workrelated rumination are recommended. In this regard cognitive behaviour therapy (Querstret \& Cropley, 2013; Querstret, Cropley, Kruger, \& Heron, 2015) and mindfulness-based interventions (Querstret, Cropley, \& Fife-Schaw, 2017) for changing ways of thinking and focusing on the present have shown to be effective. An efficient low-cost intervention to prevent rumination is instructing employees to set daily goals and to create an action plan at the end of the day for (a) where, (b) when and (c) how they will accomplish unachieved goals (Smit, 2016). This intervention is based on the fact that unexpectedly slow progress in goal attainment can trigger rumination (Martin \& Tesser, 1996; Syrek \& Antoni, 2014).

In addition, our results suggest that decreasing exhaustion and increasing vigour at work are advisable. In this regard job crafting - proactive behaviours that employees engage in to increase challenge and to decrease hindrance job demands, as well as to increase structural and social job resources (Tims, Bakker, \& Derks, 2012) - may be productive (see Rudolph, Katz, Lavigne, \& Zacher, 2017, for a meta-analysis). Decreasing job demands, in particular, may decrease exhaustion and increasing job resources may increase vigour.

\section{Limitations and Future Directions}


There are several limitations to be taken into account. First, the response rates were relatively low (i.e., $37.5 \%$ at $\mathrm{T} 1,23.4 \%$ at $\mathrm{T} 2$ and $18.5 \%$ at $\mathrm{T} 3$ relative to baseline respondents) which raises the possibility that response bias may affect the generalizability of our results. However, the response rate at baseline was not lower than those typical of studies conducted in organizations (see Baruch \& Holtom, 2008, for a review). The dropout analyses revealed that dropout was related to background factors (temporary employment contract, other than day shift and older age). Attrition was also connected to the study variables (affective rumination, exhaustion and vigour). Therefore our results may be biased owing to minor self-selection, which is typical of longitudinal studies. Attrition may also relate to the fact that we were able to follow-up only those employees who did not transfer to another organization. In the future it would be important to be able also to follow-up job-changers and thereby to avoid dropouts. Nevertheless, we found significant effects and had a diverse and large sample, which adds to the generalizability of our results.

Second, our study was based on self-report measures and may be susceptible to common method bias. However, our longitudinal study design and the use of established scales with good psychometric properties may have reduced the degree of common method variance (Podsakoff, MacKenzie, Lee, \& Podsakoff, 2003). Nonetheless, future studies could reduce common method variance by applying significant others’ reports of a person's level of rumination during off-job time. Third, we used shortened scales in order to limit the length of the questionnaire because this study was part of a larger research project. Although this may jeopardize the construct validity of the scales, we are confident that it hardly affects our measures, which were shown to be timeinvariant with high item loadings and high internal reliability, except for problem-solving pondering, of which reliability remained slightly below .70. This may suggest that there was too much variety in the content of the items (e.g., problem-solving and creativity were included) and therefore the short measure functioned as an index rather than as a scale, implying that internal consistency may not be a good criterion for this measure (Streiner, 2003). 
Fourth, the differences between the three work-related rumination concepts deserve more attention in the future. For example, as psychological detachment from work implies a state during which the individual is capable of dispelling all thoughts of work - including positive work reflection - its position needs further clarification. It could be good to ascertain more directly which kind of work-related thoughts (negative vs. positive) employees detach themselves from. This differentiation could help to further clarify the relationship between lack of detachment, affective rumination and problem-solving pondering.

\section{Conclusions}

To conclude, the present study showed that the lagged effects between work-related rumination and well-being may run in both directions and that the time lag between measurements matters. Reversed effects gained most support, indicating that level of energy was important in determining type of ruminative thoughts. The reversed relationship from high vigour to low affective rumination was supported both across one and two years and high exhaustion had a lagged effect on low problem-solving pondering across two years. The lagged effect from high affective rumination to high exhaustion across one year was the only relationship following normal effect model.

\section{References}

Baruch, Y., \& Holtom, B. (2008). Survey response rate levels and trends in organizational research. Human Relations, 61, 1139-1160. doi:10.1177/0018726708094863

Bennett, A., Bakker, A. B., \& Field, J. G. (2018). Recovery from work-related effort: A metaanalysis. Journal of Organizational Behavior, 39, 262-275. doi: 10.1002/job2217

Bennett, A., Gabriel, A., Calderwood, C., Dahling, J., \& Trougakos, J. (2016). Better together? Examining profiles of employee recovery experiences. Journal of Applied Psychology, 101, 1635-1654. doi:10.1037/apl0000157

Berset, M., Elfering, A., Luthy, S., Luthi, S., \& Semmer, N. K. (2011). Work stressors and impaired 
sleep: rumination as a mediator. Stress and Health, 27, e71-e82. doi:10.1002/smi.1337

Brosschot, J. F., Gerin, W., \& Thayer, J. F. (2006). The perseverative cognition hypothesis: A review of worry, prolonged stress-related physiological activation and health. Journal of Psychosomatic Research, 60, 113-124. doi:10.1016/j.jpsychores.2005.06.074

Cropley, M., Michalianou, G., Pravettoni, G., \& Millward, L. (2012). The relation of post work ruminative thinking with eating behaviour. Stress and Health, 28, 23-30. doi:10.1002/ smi.1397

Cropley, M., \& Zijlstra, F. R. H. (2011). Work and rumination. In J. Langan-Fox \& C. L. Cooper (Eds.), Handbook of stress in the occupations (pp. 487-502). Northampton, MA: Elgar.

Demerouti, E., Moster, K., \& Bakker, A. (2010). Burnout and work engagement: A thorough investigation of the independency of both constructs. Journal of Occupational Health Psychology, 15, 209-222. doi:10.1037/a0019408

Dormann, C., \& Griffin, M. (2015). Optimal time lags in panel studies. Psychological Methods, 20, 489-505. doi:10.1037/met0000041

Etzion, D., Eden, D., \& Lapidot, Y. (1998). Relief from job stressors and burnout: Reserve service as a respite. Journal of Applied Psychology, 83, 577-585. doi:10.1037/0021-9010.83.4.577

Feuerhahn, N., Stamov-Roßnagel,C., Wolfram, M., Bellingrath, S., \& Kudielka, B. M. (2013). Emotional exhaustion and cognitive performance in apparently healthy teachers: A longitudinal multi-source study. Stress and Health, 29, 297-306. doi:10.1002/smi.2467

Finch, J. F., Baranik, L. E., Liu, Y., \& West, S. G. (2012). Physical health, positive and negative affect, and personality: A longitudinal analysis. Journal of Research in Personality, 46, 537545. doi: 10.1016/j.jrp.2012.05.013

Firoozabadi, A., Uitdewilligen, S., \& Ziljstra, F. R. H. (2016). Should you switch off or stay engaged? The consequences of thinking about work on the trajectory of psychological wellbeing over time. Journal of Occupational Health Psychology. Advance online publication. 
doi:10.1037/ocp0000068

Ford, M. T., Matthews, R. A., Wooldridge, J. D., Mishra, V., Kakar, U. M., \& Strahan, S. R. (2014). How do occupational stressor-strain effects vary with time? A review and metaanalysis of the relevance of time lags in longitudinal studies. Work \& Stress, 28, 9-30. doi: 10.1080/02678373.2013.877096

Fredrickson, B. L. (1998). What good are positive emotions? Review of General Psychology, 2, 300-319. doi:10.1037/1089-2680.2.3.300

Fredrickson, B. L., \& Joiner, T. (2002). Positive emotions trigger upward spirals toward emotional well-being. Psychological Science, 13, 172-175. doi:10.1111/1467-9280.00431

Geurts, S. A. E., \& Sonnentag, S. (2006). Recovery as an explanatory mechanism in the relation between acute stress reactions and chronic health impairment. Scandinavian Journal of Work, Environment and Health, 32, 482-492. doi:10.5271/sjweh.1053

Hamesch, U., Cropley, M., \& Lang, J. (2014). Emotional versus cognitive rumination: Are they differently affecting long-term psychological health? The impact of stressors and personality in dental students. Stress and Health, 30, 222-231. doi:10.1002/smi.2602

Hobfoll, S. E. (2001). The influence of culture, community, and the nested self in the stress process: Advancing conservation of resources theory. Applied Psychology: An International Review, 50, 337-370. doi:10.1111/1464-0597.00062

Hu, L., \& Bentler, P. M. (1999). Cutoff criteria for fit indexes in covariance structure analysis: Conventional criteria versus new alternatives. Structural Equation Modeling, 6, 1-55. doi: $10.1080 / 10705519909540118$

Kalimo, R., Hakanen, J., \& Toppinen-Tanner, S. (2006). Maslachin yleinen työuupumuksen arviointimenetelmä MBI-GS. [The Finnish version of the Maslach Burnout Inventory General Survey]. Helsinki: Finnish Institute of Occupational Health.

Kelloway, E. K., \& Francis, L. (2013). Longitudinal research and data analysis. In L. Tetric, M. 
Wang \& R. Sinclair (Eds.), Research methods in occupational health psychology:

Measurement, design, and data analysis (pp. 374-303). New York: Routledge.

Kinnunen, U., \& Feldt, T. (2013). Job characteristics, recovery experiences and occupational wellbeing: Testing cross-lagged relationships across 1 year. Stress and Health, 29, 369-382. doi: 10.1002/smi.2483

Kinnunen, U., Feldt, T., Sianoja, M., De Bloom, J., Korpela, K., \& Geurts, S. (2017). Identifying long-term patterns of work-related rumination: Associations with job demands and well-being outcomes. European Journal of Work and Organizational Psychology, 26, 514-526. doi: 10.1080/1359432X.2017.1314265

Kinnunen, U., Feldt, T., Siltaloppi, U., \& Sonnentag, S. (2011). Job demands-resources model in the context of recovery: Testing recovery experiences as mediators. European Journal of Work and Organizational Psychology, 20, 805-832. doi:10.1080/1359432X.2010.524411

Leiter, M. P., \& Bakker, A. B. (2010). Work engagement: Introduction. In A. B. Bakker \& M P. Leiter (Eds.), Work engagement. A handbook of essential theory and research (pp.1-9). New York: Psychology Press.

Martin, L. L., \& Tesser, A. (1996). Some ruminative thoughts. In R. S. Wyer (Ed.), Advances in social cognition (Vol. IX, pp. 1-47). Hillsdale, NJ: Erlbaum.

Maslach, C., Jackson, S., \& Leiter, M. P. (1996). MBI: Maslach Burnout Inventory manual (3rd edn). Palo Alto: Consulting Psychologists Press.

Maslach, C., Schaufeli, W. B., \& Leiter, M. P. (2001). Job burnout. Annual Review of Psychology, 52, 397-422. doi:10.1146/annurev.psych.52.1.397

Meijman, T. F., \& Mulder, G. (1998). Psychological aspects of workload. In P. J. D. Drenth \& H. Thierry (Eds.), Handbook of work and organizational psychology: Vol. 2. Work psychology (pp. 5-33). Hove, UK: Psychology Press.

Muraven, M., \& Baumeister, R. F. (2000). Self-regulation and depletion of limited resources: Does 
self-control resemble a muscle? Psychological Bulletin, 126, 247-259. doi: 10.1037/00332909.126.2.247

Muthén, L. K., \& Muthén, B. O. (1998-2012). Mplus User’s Guide. 6th Ed. Los Angeles, CA: Muthén \& Muthén.

Mäkikangas, A., Feldt, T., Kinnunen, U., \& Tolvanen, A. (2012). Do low burnout and high work engagement always go hand in hand? Investigation of the energy and identification dimensions in longitudinal data. Anxiety, Stress, \& Coping, 25, 93-116. doi:10.1080/ 10615806.2011.565411

Ottaviani, C., Thayer, J. F., Verkuil, B., Lonigro, A., Medea, B., Couyoumdjian, A., \& Brosschot, J. F. (2016). Physiological concomitants of perseverative cognition: A systematic review and meta-analysis. Psychological Bulletin, 142, 231-259. doi: 10.1037/bul0000036

Podsakoff, P. M., MacKenzie, S. B., Lee, J.-Y., \& Podsakoff, N. P. (2003). Common method biases in behavioral research: A critical review of the literature and recommended remedies. Journal of Applied Psychology, 88, 879-903. doi:10.1037/0021-9010.88.5.879

Pravettoni, G., Cropley, M., Leotta, S. N., \& Bagnara, S. (2007). The differential role of mental rumination among industrial and knowledge workers. Ergonomics, 50, 1931-1940. doi: $10.1080 / 00140130701676088$

Querstret, D., \& Cropley, M. (2012). Exploring the relationship between work-related rumination, sleep quality, and work-related fatigue. Journal of Occupational Health Psychology, 17, 341353. doi:10.1037/10028552

Querstret, D., \& Cropley, M. (2013). Assessing treatments used to reduce rumination and/or worry: A systematic review. Clinical Psychology Review, 33, 996-1009. doi:10.1016/ j.cpr.2013.08.004

Querstret, D., Cropley, M., \& Fife-Schaw, C. (2017). Internet-based instructor-led mindfulness for work-related rumination, fatigue, and sleep: Assessing facets of mindfulness as mechanisms 
of change. A randomized waitlist control trial. Journal of Occupational Health Psychology, 22, 153-169. doi:10.1037/ocp0000028

Querstret, D., Cropley, M., Kruger, P., \& Heron, R. (2015). Assessing the effect of a Cognitive Behaviour Therapy (CBT)-based workshop on work-related rumination, fatigue, and sleep. European Journal of Work and Organizational Psychology, 25, 50-67. doi:10.1080/ 1359432X.2015.1015516

Rudolph, C. W., Katz, I. M., Lavigne, K. N., \& Zacher, H. (2017). Job crafting: a meta-analysis of relationships with individual differences, job characteristics, and work outcomes. Journal of Vocational Behavior, 102, 112-138. doi:10.1016/j.jvb.2017.05.008

Satorra, A., \& Bentler, P. M. (2001). A scaled difference chi-square test statistics for moment structure analysis. Psychometrika, 66, 507-514. doi: 10.1007/BF02296192

Schaufeli, W. B., \& Enzmann, D. (1998). The burnout companion to study and practice: A critical analysis. Washington, DC: Taylor \& Francis.

Schaufeli, W. B., Bakker, A. B., \& Salanova, M. (2006). The measurement of work engagement with a short questionnaire. Educational and Psychological Measurement, 66, 701-716. doi: $10.1177 / 0013164405282471$

Schaufeli, W. B., Salanova, M., González-Romá, V., \& Bakker, A. B. (2002). The measurement of engagement and burnout: A two sample confirmatory factor analytic approach. Journal of Happiness Studies, 3, 71-92. doi:10.1023/A:1015630930326

Segerstrom, S. C., Stanton, A. L., Alden, L. E., \& Shortridge, B. E. (2003). A multidimensional structure for repetitive thought: What's on your mind, and how, and how much? Journal of Personality and Social Psychology, 85, 909-921. doi:10.1037/0022-3514.85.5.909

Seo, M. G., Barrett, L. F., \& Bartunek, J. M. (2004). The role of affective experience in work motivation. The Academy of Management Review, 29, 423-439.

Seppälä, P., Mauno, S., Feldt, T., Hakanen, J., Kinnunen, U., Tolvanen, A., \& Schaufeli, W. B. 
(2009). The construct validity of the Utrecht Work Engagement Scale: Multi-sample and longitudinal evidence. Journal of Happiness Studies, 10, 459-481. doi:10.1007/s10902-008$9100-y$

Shirom, A. (2010). Feeling energetic at work: On vigor's antecedents. In A. B. Bakker \& M. P. Leiter (Eds.), Work engagement - A handbook of essential theory and research (pp. 69-84). New York: Psychology Press.

Sianoja, M., Kinnunen, U., Mäkikangas, A., \& Tolvanen, A. (2018). Testing the direct and moderator effects of the stressor-detachment model over one year: A latent change perspective. Work \& Stress, 32, 357-378. doi: 10.1080/02678373.2018.1437232

Sluiter, J. K., Frings-Dresen, M. H. W., van der Beek, A. J., \& Meijman, T. F. (2001). The relation between work-induced neuroendocrine reactivity and recovery, subjective need for recovery, and health status. Journal of Psychosomatic Research, 50, 29-37. doi: 10.1016/S00223999(00)00213-0

Smit, B. W. (2016). Successfully leaving work at work: The self-regulatory underpinnings of psychological detachment. Journal of Occupational and Organizational Psychology, 89, 493-514. doi: 10.1111/joop.12137

Sonnentag, S., Arbeus, H., Mahn, C., \& Fritz, C. (2014). Exhaustion and lack of psychological detachment from work during off-job time: moderator effects of time pressure and leisure experiences. Journal of Occupational Health Psychology, 19, 206-216. doi:

10.1037/a0035760

Sonnentag, S., Binnewies, C., \& Mojza, E. J. (2010). Stay well and engaged when demands are high: the role of psychological detachment. Journal of Applied Psychology, 95, 965-976. doi: $10.1037 / \mathrm{a} 0020032$

Sonnentag, S., \& Fritz, C. (2007). The Recovery Experience Questionnaire: Development and validation of a measure for assessing recuperation and unwinding from work. Journal of 
Occupational Health Psychology, 12, 204-221. doi:10.1037/1076-8998.12.3.204

Sonnentag, S., \& Fritz, C. (2015). Recovery from job stress: The stressor-detachment model as an integrative framework. Journal of Organizational Behavior, 36, 72-103. doi:10.1002/ job. 1924

Sonnentag, S., \& Geurts, S. A. E. (2009). Methodological issues in recovery research. In S.

Sonnentag, P. Perrewé, \& D. Ganster (Eds.), Currents perspectives on job-stress recovery (pp. 1-36). Bingley, UK: Emerald.

Sonnentag, S., \& Grant, A. M. (2012). Doing good at work feels good at home, but not right away: When and why perceived prosocial impact predicts positive affect. Personnel Psychology, 65(3), 495-530. doi: 10.1111/j.1744-6570.2012.01251.x

Sonnentag, S., Venz, L., \& Casper, A. (2017). Advances in recovery research: What have we learned? What should be done next? Journal of Occupational Health Psychology, 22, 365380. doi:10.1037/ocp0000079

Spector, P. E., \& Jex, S. M. (1998). Development of four self-report measures of job stressors and strain: Interpersonal conflict at work scale, organizational constraints scale, quantitative workload inventory, and physical symptoms inventory. Journal of Occupational Health Psychology, 3, 356-367. doi: 10.1037/1076-8998.3.4.356

Streiner, D. L. (2003). Being inconsistent about consistency: when coefficient alpha does and doesn’t matter. Journal of Personality Assessment, 80, 217-222. doi: 10.1207/S15327752JPA8003_01

Syrek, C., \& Antoni, C. (2014). Unfinished tasks foster rumination and impair sleeping particularly if leaders have high performance expectations. Journal of Occupational Health Psychology, 19, 490-499. doi:10.1037/a0037127

Syrek, C., Weigelt, O., Peifer, C., \& Antoni, C. (2017). Zeigarnik’s sleepless nights: How unfinished tasks at the end of the week impair employee sleep on the weekend through 
rumination. Journal of Occupational Health Psychology, 22, 225-238. doi:

10.1037/ocp0000031

Taris, T. W., \& Kompier, M. A. J. (2014). Cause and effect: Optimizing the designs of longitudinal studies in occupational health psychology. Work \& Stress, 28, 1-8. doi:

$10.1080 / 02678373.2014 .878494$

Tims, M., Bakker, A. B., \& Derks, D. (2012). Development and validation of the job crafting scale. Journal of Vocational Behavior, 80, 173-186. doi:10.1016/j.jvb.2011.05.009

Vahle-Hinz, T., Mauno, S., De Bloom, J., \& Kinnunen, U. (2017). Rumination for innovation? Analyzing the longitudinal effects of work-related rumination on creativity at work and offjob recovery. Work \& Stress, 31, 315-337. doi: 10.1080/02678373.2017.1303761

van der Linden, D., Keijsers, G. J., Eling, P., \& van Schaijk, R. (2005). Work stress and attentional difficulties: An initial study on burnout and cognitive failures. Work \& Stress, 19, 23-36. doi: $10.1080 / 02678370500065275$

van Veldhoven, M. (2008). Need for recovery after work. An overview of construct, measurement and research. In J. Houdmont \& S. Leka (Ed.), Occupational health psychology: European perspectives on research, education and practice (pp. 1-25). Nottingham: Nottingham University Press.

Vuori, M., Akila, R., Kalakoski, V., Pentti, J., Kivimäki, M., Vahtera, J., Härmä, M., \& Puttonen, S. (2014). Association between exposure to work stressors and cognitive performance. Journal of Occupational and Environmental Medicine, 56, 354-360. doi: 10.1097/ JOM.0000000000000129

Wendsche, J., \& Lohmann-Haislah, A. (2017). A meta-analysis on antecedents and outcomes of detachment from work. Frontiers in Psychology, 7, 2072. doi: 10.3389/psyg.2016.02072 Zijlstra, F. R. H., Cropley, M., \& Rydstedt, W. (2014). From recovery to regulation: An attempt to reconceptualize 'recovery from work'. Stress and Health, 30, 244-252. doi:10.1002/smi.2604 
Table 1

Correlations of the Study Variables $(n=645-664)$

\begin{tabular}{|c|c|c|c|c|c|c|c|c|c|c|c|c|c|c|c|c|c|c|}
\hline Variables & $M$ & $S D$ & 1 & 2 & 3 & 4 & 5 & 6 & 7 & 8 & 9 & 10 & 11 & 12 & 13 & 14 & 15 & 16 \\
\hline 1. Time pressure T1 & 3.87 & 0.82 & .88 & & & & & & & & & & & & & & & \\
\hline 2. Affective rumination $\mathrm{T} 1$ & 2.43 & 0.88 & .27 & .87 & & & & & & & & & & & & & & \\
\hline 3. Pondering T1 & 2.88 & 0.77 & .21 & .19 & .68 & & & & & & & & & & & & & \\
\hline 4. Detachment at $\mathrm{T} 1$ & 2.98 & 0.97 & -.21 & -.33 & -.55 & .86 & & & & & & & & & & & & \\
\hline 5. Job exhaustion at T1 & 1.86 & 1.43 & .38 & .57 & .17 & -.29 & .93 & & & & & & & & & & & \\
\hline 6. Vigour T1 & 4.58 & 1.19 & .00 & -.39 & .07 & .12 & -.47 & .89 & & & & & & & & & & \\
\hline 7. Affective rumination $\mathrm{T} 2$ & 2.43 & 0.89 & .26 & .66 & .14 & -.28 & .45 & -.34 & .89 & & & & & & & & & \\
\hline 8. Pondering T2 & 2.88 & 0.74 & .10 & .14 & .69 & -.44 & .10 & .10 & .13 & .68 & & & & & & & & \\
\hline 9. Detachment T2 & 3.03 & 0.97 & -.18 & -.27 & -.45 & .62 & -.20 & .09 & -.31 & -.49 & .86 & & & & & & & \\
\hline 10. Job exhaustion T2 & 1.90 & 1.42 & .33 & .48 & .10 & -.24 & .69 & -.35 & .57 & .05 & -.25 & .93 & & & & & & \\
\hline 11. Vigour T2 & 4.44 & 1.30 & .05 & -.31 & .05 & .12 & -.34 & .68 & -.41 & .13 & .14 & -.45 & .91 & & & & & \\
\hline 12. Affective rumination T3 & 2.46 & 0.89 & .15 & .56 & .06 & -.19 & .39 & -.32 & .70 & 03 & -.21 & .48 & -.36 & .89 & & & & \\
\hline 13. Pondering T3 & 2.95 & 0.76 & .18 & .09 & .70 & -.46 & .06 & .13 & .11 & .72 & -.48 & .05 & .11 & .07 & .70 & & & \\
\hline 14. Detachment T3 & 3.01 & 0.95 & -.12 & -.20 & -.43 & .59 & -.17 & .08 & -.26 & -.42 & .65 & -.19 & .12 & -.29 & -.51 & .85 & & \\
\hline 15. Job exhaustion T3 & 1.92 & 1.44 & .26 & .36 & .11 & -.19 & .58 & .31 & .48 & .07 & -.21 & .70 & .37 & .57 & .08 & -.28 & .93 & \\
\hline 16. Vigour T3 & 4.44 & 1.32 & .06 & -.24 & .05 & .11 & -.28 & .64 & -.34 & .10 & .12 & -.37 & .71 & -.42 & .13 & .17 & -.49 & .91 \\
\hline
\end{tabular}

Note. If $r \geq|.13|, p<.001$. Cronbach's alphas are shown on the diagonal. 
Table 2

Goodness of Fit Statistics for the Tested Cross-lagged SEM-models between Work-Related Rumination and Job Exhaustion (T1-T2-T3, T1-T3)

\begin{tabular}{|c|c|c|c|c|c|c|c|}
\hline \multirow[b]{2}{*}{ T1-T2-T3 } & \multicolumn{4}{|c|}{ Model fit } & & \multicolumn{2}{|c|}{ Model comparison } \\
\hline & $\chi^{2}(\mathrm{df})$ & RMSEA & SRMR & TLI & CFI & Model & $\Delta \chi^{2}(\mathrm{df})$ \\
\hline \multicolumn{8}{|c|}{ Affective rumination } \\
\hline M0 & $828.77(229)$ & 0.06 & 0.06 & 0.94 & 0.95 & & \\
\hline M1 & $851.14(241)$ & 0.06 & 0.07 & 0.94 & 0.95 & M1 vs. M0 & $14.90(6)$ \\
\hline M2 & 834.36 (239) & 0.06 & 0.04 & 0.94 & 0.95 & M2 vs. M1 & $15.87(2)^{* * *}$ \\
\hline M3 & 844.34 (239) & 0.06 & 0.05 & 0.94 & 0.95 & M3 vs. M1 & $6.80(2)^{*}$ \\
\hline \multirow[t]{2}{*}{ M4 } & $831.72(237)$ & 0.06 & 0.04 & 0.94 & 0.95 & M4 vs. M1 & $19.16(4)^{* * *}$ \\
\hline & & & & & & M4 vs. M2 & $2.64(2)$ \\
\hline \multicolumn{8}{|l|}{ Pondering } \\
\hline M0 & 1140.27 (229) & 0.08 & 0.10 & 0.91 & 0.90 & & \\
\hline M1 & $1157.54(241)$ & 0.08 & 0.10 & 0.90 & 0.91 & M1 vs. M0 & $3.76(12)$ \\
\hline M2 & 1156.37 (239) & 0.08 & 0.10 & 0.90 & 0.91 & M2 vs. M1 & $1.99(2)$ \\
\hline M3 & $1153.06(239)$ & 0.08 & 0.10 & 0.90 & 0.91 & M3 vs. M1 & $4.48(2)$ \\
\hline M4 & $1151.96(237)$ & 0.08 & 0.10 & 0.90 & 0.91 & M4 vs. M1 & $6.28(4)$ \\
\hline \multicolumn{8}{|l|}{ Detachment } \\
\hline M0 & 791.76 (229) & 0.06 & 0.04 & 0.94 & 0.95 & & \\
\hline M1 & $809.26(241)$ & 0.06 & 0.04 & 0.94 & 0.95 & M1 vs. M0 & $8.32(12)$ \\
\hline M2 & 807.07 (239) & 0.06 & 0.04 & 0.94 & 0.95 & M2 vs. M1 & $2.19(2)$ \\
\hline M3 & 809.92 (239) & 0.06 & 0.04 & 0.94 & 0.95 & M3 vs. M1 & $0.67(2)$ \\
\hline M4 & 807.75 (237) & 0.06 & 0.04 & 0.94 & 0.95 & M4 vs. M1 & $2.13(4)$ \\
\hline \multicolumn{8}{|l|}{ T1-T3 } \\
\hline \multicolumn{8}{|c|}{ Affective rumination } \\
\hline M0 & $363.72(92)$ & 0.07 & 0.04 & 0.95 & 0.96 & & \\
\hline M1 & 375.56 (98) & 0.07 & 0.04 & 0.95 & 0.96 & M1 vs. M0 & $8.94(6)$ \\
\hline M2 & 374.44 (97) & 0.07 & 0.04 & 0.95 & 0.96 & M2 vs. M1 & $8.72(1)$ \\
\hline M3 & 373.28 (97) & 0.07 & 0.03 & 0.95 & 0.96 & M3 vs. M1 & $2.14(1)$ \\
\hline M4 & $373.14(96)$ & 0.07 & 0.03 & 0.96 & 0.95 & M4 vs. M1 & $2.20(1)$ \\
\hline \multicolumn{8}{|l|}{ Pondering } \\
\hline M0 & $461.648(92)$ & 0.08 & 0.09 & 0.92 & 0.94 & & \\
\hline M1 & 466.466 (98) & 0.08 & 0.09 & 0.93 & 0.94 & M1 vs. M0 & $0.76(6)$ \\
\hline M2 & $466.528(97)$ & 0.08 & 0.09 & 0.93 & 0.94 & M2 vs. M1 & $0.22(1)$ \\
\hline M3 & 460.218 (97 & 0.08 & 0.09 & 0.93 & 0.94 & M3 vs. M1 & $6.22(1)^{* *}$ \\
\hline \multirow[t]{2}{*}{ M4 } & $460.288(96)$ & 0.08 & 0.09 & 0.93 & 0.94 & M4 vs. M1 & $6.29(2)^{*}$ \\
\hline & & & & & & M4 vs. M3 & $0.17(1)$ \\
\hline \multicolumn{8}{|l|}{ Detachment } \\
\hline M0 & 333.92 (92) & 0.06 & 0.03 & 0.95 & 0.96 & & \\
\hline M1 & 345.50 (98) & 0.06 & 0.03 & 0.95 & 0.96 & M1 vs. M0 & $9.54(6)$ \\
\hline M2 & 345.52 (97) & 0.06 & 0.03 & 0.95 & 0.96 & M2 vs. M1 & $0.26(1)$ \\
\hline M3 & 345.26 (97) & 0.06 & 0.03 & 0.95 & 0.96 & M3 vs. M1 & $0.24(1)$ \\
\hline M4 & $345.26(96)$ & 0.06 & 0.03 & 0.95 & 0.96 & M4 vs. M1 & $0.52(2)$ \\
\hline
\end{tabular}

Notes. M0 = free stability model, M1 = constrained stability model, M2 = normal effect model, M3 = reversed effect model, M 4 = reciprocal effect model. RMSEA = root mean square of approximation, SRMR = standardized root mean square residual [values $\leq 0.08$ indicate a good data fit]; TLI $=$ Tucker Lewis Index, CFI $=$ Comparative Fit Index [values close to 0.95 indicate a good fit of the model (Hu \& Bentler, 1999)]. * $p<.05, * * p<.01, * * * p<.001$. 
Table 3

Goodness of Fit Statistics for the Tested Cross-lagged SEM-models between Work-Related Rumination and Vigour at Work (T1-T2-T3, T1-T3)

\begin{tabular}{|c|c|c|c|c|c|c|c|}
\hline \multirow[b]{2}{*}{ T1-T2-T3 } & \multicolumn{5}{|c|}{ Model fit } & \multicolumn{2}{|c|}{ Model comparison } \\
\hline & $\chi^{2}(\mathrm{df})$ & RMSEA & SRMR & TLI & CFI & Model & $\Delta \chi^{2}(\mathrm{df})$ \\
\hline \multicolumn{8}{|c|}{ Affective rumination } \\
\hline M0 & 404.85 (116) & 0.06 & 0.08 & 0.95 & 0.96 & & \\
\hline M1 & $417.75(124)$ & 0.06 & 0.08 & 0.96 & 0.96 & M1 vs. M0 & $12.11(8)$ \\
\hline M2 & $413.98(122)$ & 0.06 & 0.08 & 0.96 & 0.96 & M2 vs. M1 & $3.92(2)$ \\
\hline M3 & $409.96(122)$ & 0.06 & 0.07 & 0.96 & 0.96 & M3 vs. M1 & $7.79(2)^{*}$ \\
\hline \multirow[t]{2}{*}{ M4 } & $407.18(120)$ & 0.06 & 0.07 & 0.95 & 0.96 & M4 vs. M1 & $10.57(4)^{*}$ \\
\hline & & & & & & M4 vs. M3 & $2.78(2)$ \\
\hline \multicolumn{8}{|l|}{ Pondering } \\
\hline M0 & $571.30(116)$ & 0.08 & 0.08 & 0.91 & 0.94 & & \\
\hline M1 & $579.25(124)$ & 0.07 & 0.08 & 0.92 & 0.94 & M1 vs. M0 & $4.83(8)$ \\
\hline M2 & $578.70(122)$ & 0.08 & 0.08 & 0.92 & 0.94 & M2 vs. M1 & $0.04(2)$ \\
\hline M3 & $576.51(122)$ & 0.08 & 0.08 & 0.92 & 0.94 & M3 vs. M1 & $0.88(2)$ \\
\hline M4 & $575.10(120)$ & 0.08 & 0.08 & 0.92 & 0.94 & M4 vs. M1 & $1.84(4)$ \\
\hline \multicolumn{8}{|l|}{ Detachment } \\
\hline M0 & 373.09 (116) & 0.06 & 0.06 & 0.96 & 0.97 & & \\
\hline M1 & $384.69(124)$ & 0.06 & 0.06 & 0.96 & 0.97 & M1 vs. M0 & $10.14(8)$ \\
\hline M2 & 383.65 (122) & 0.06 & 0.06 & 0.96 & 0.97 & M2 vs. M1 & $1.57(2)$ \\
\hline M3 & $384.43(122)$ & 0.06 & 0.06 & 0.96 & 0.97 & M3 vs. M1 & $0.26(2)$ \\
\hline M4 & 383.46 (120) & 0.06 & 0.06 & 0.96 & 0.97 & M4 vs. M1 & $2.12(4)$ \\
\hline \multicolumn{8}{|l|}{ T1-T3 } \\
\hline \multicolumn{8}{|c|}{ Affective rumination } \\
\hline M0 & $127.13(44)$ & 0.05 & 0.06 & 0.97 & 0.98 & & \\
\hline M1 & $134.97(48)$ & 0.05 & 0.06 & 0.97 & 0.98 & M1 vs. M0 & $7.80(4)$ \\
\hline M2 & $134.48(47)$ & 0.05 & 0.06 & 0.97 & 0.98 & M2 vs. M1 & $0.03(1)$ \\
\hline M3 & $128.98(47)$ & 0.05 & 0.05 & 0.97 & 0.98 & M3 vs. M1 & $6.27(1)^{* *}$ \\
\hline \multirow[t]{2}{*}{ M4 } & $128.98(47)$ & 0.05 & 0.05 & 0.97 & 0.98 & M4 vs. M1 & $6.88(2)^{*}$ \\
\hline & & & & & & M4 vs. M3 & 0.35 (1) \\
\hline \multicolumn{8}{|l|}{ Pondering } \\
\hline M0 & $104.50(44)$ & 0.05 & 0.06 & 0.98 & 0.99 & & \\
\hline M1 & $106.66(48)$ & 0.04 & 0.06 & 0.98 & 0.99 & M1 vs. M0 & $2.44(4)$ \\
\hline M2 & $106.60(47)$ & 0.04 & 0.06 & 0.98 & 0.99 & M2 vs. M1 & $0.15(1)$ \\
\hline M3 & $104.44(47)$ & 0.04 & 0.06 & 0.98 & 0.99 & M3 vs. M1 & $2.22(1)$ \\
\hline M4 & 104.35 (46) & 0.04 & 0.06 & 0.98 & 0.99 & M4 vs. M1 & $2.22(2)$ \\
\hline \multicolumn{8}{|l|}{ Detachment } \\
\hline M0 & $59.46(44)$ & 0.02 & 0.03 & 0.99 & 0.99 & & \\
\hline M1 & 70.09 (48) & 0.03 & 0.03 & 0.99 & 0.99 & M1 vs. M0 & $10.57(4)^{*}$ \\
\hline M2 & $69.60(47)$ & 0.03 & 0.03 & 0.99 & 0.99 & M2 vs. M1 & $0.53(1)$ \\
\hline M3 & $69.91(47)$ & 0.03 & 0.03 & 0.99 & 0.99 & M3 vs. M1 & $0.18(1)$ \\
\hline M4 & $69.40(46)$ & 0.03 & 0.03 & 0.99 & 0.99 & M4 vs. M1 & $0.69(2)$ \\
\hline
\end{tabular}

Notes. M0 = free stability model, M1 = constrained stability model, M2 = normal effect model, M3 = reversed effect model, M 4 = reciprocal effect model. RMSEA = root mean square of approximation, SRMR = standardized root mean square residual [values $\leq 0.08$ indicate a good data fit]; TLI $=$ Tucker Lewis Index, CFI = Comparative Fit Index [values close to 0.95 indicate a good fit of the model (Hu \& Bentler, 1999)]. ${ }^{*} p<.05, * * p<.01$. 
Appendix: Table 1

Summary of Hypotheses Testing

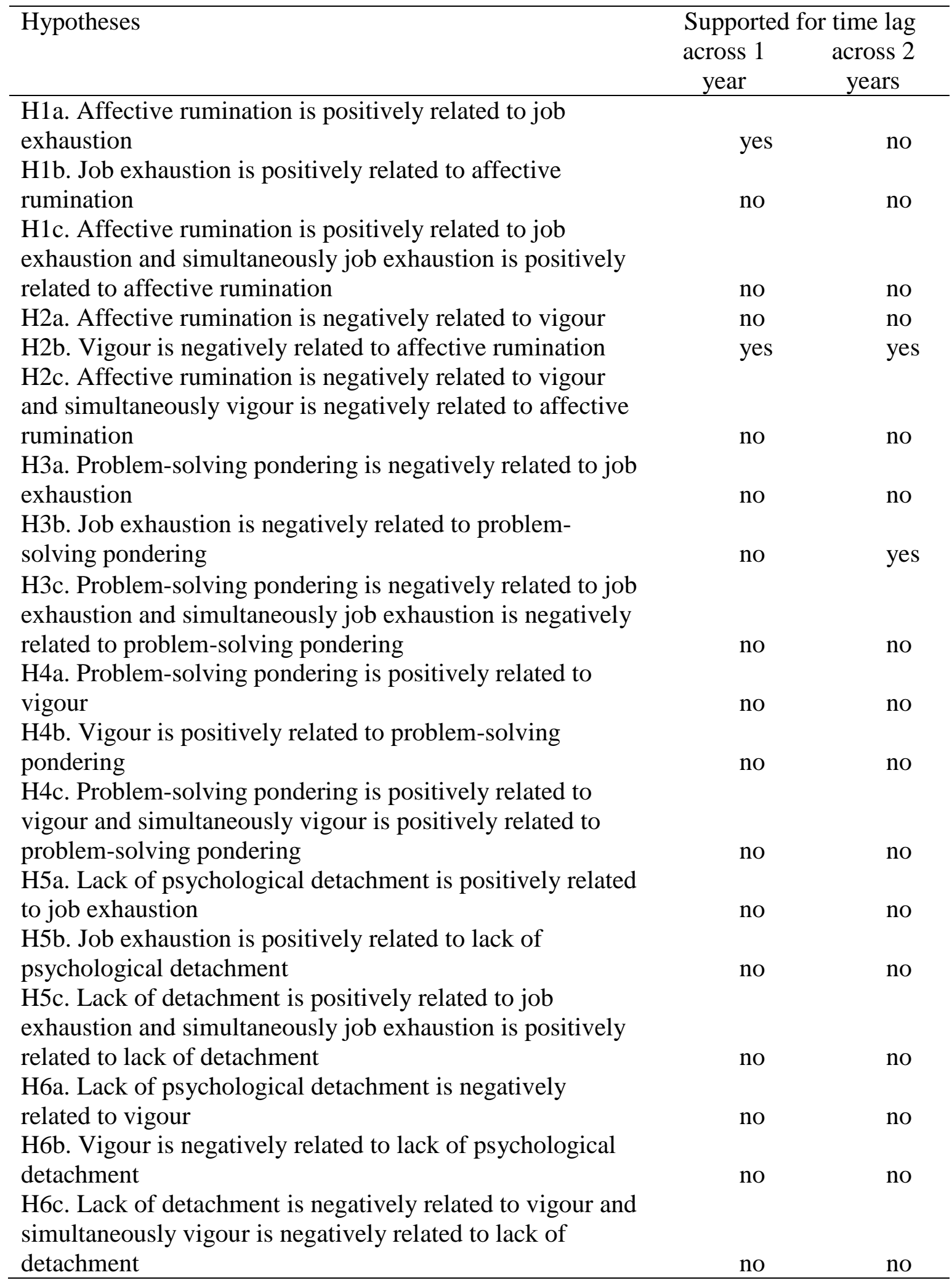




\section{Time 1}

Time 2

Time 3

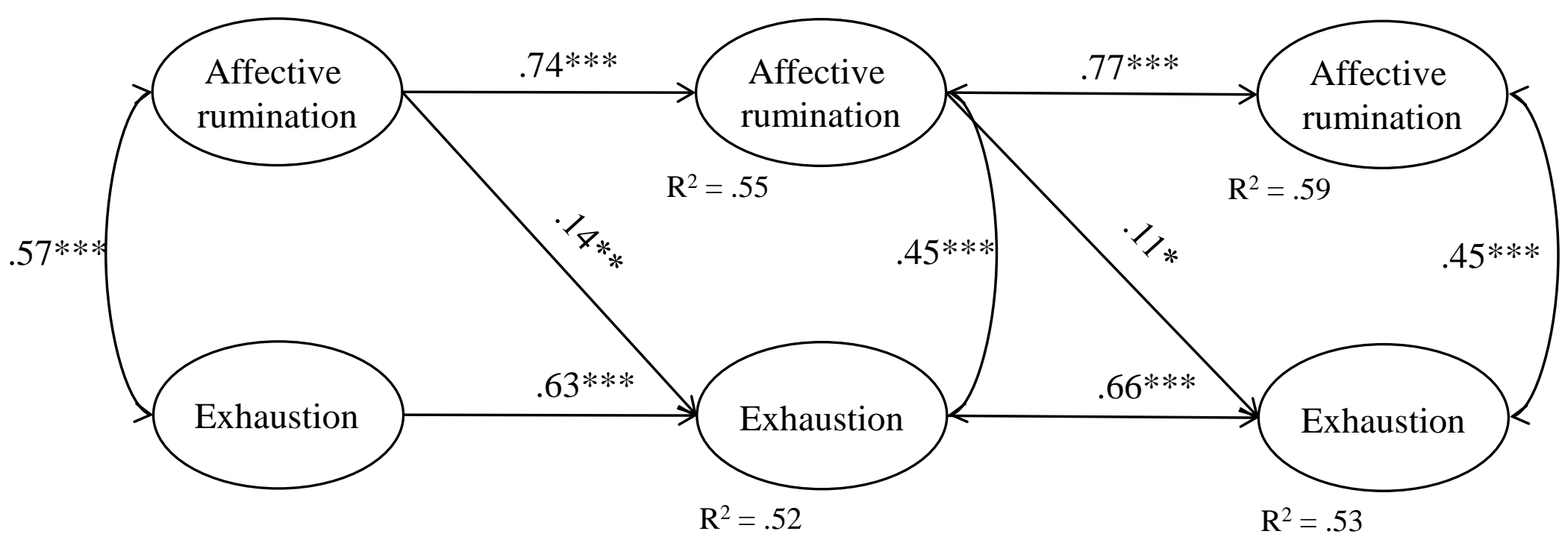

Figure 1a. Affective work-related rumination predicts job exhaustion across 1 year from T1 to T2 and from T2 to T3 follow-up (normal effects model based on three measurement points)

Notes. Time pressure at T1 controlled for in the analyses. Only significant relationships shown.

$* p<.05, * * p<.01,{ }^{* * *} p<.001$. 
Time $1 \quad$ Time 3

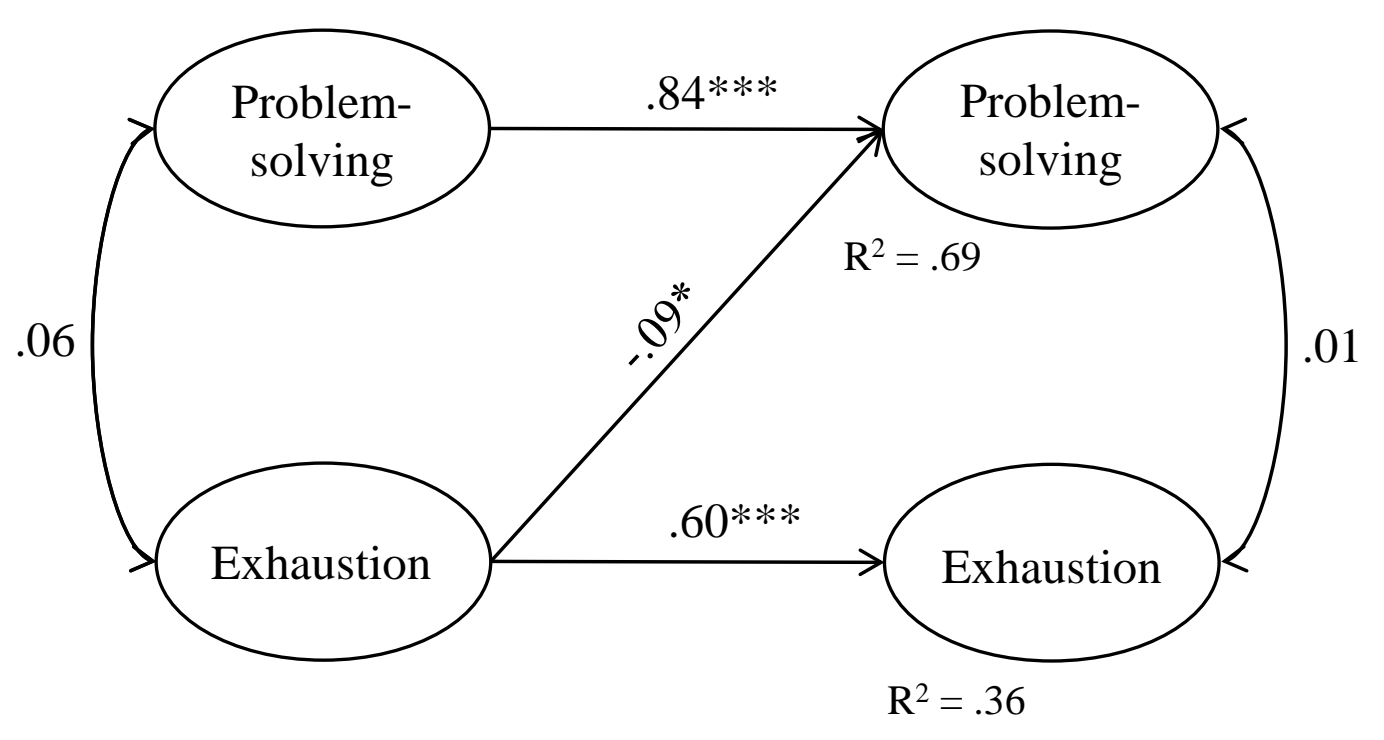

Figure $1 b$. Job exhaustion predicts problem-solving pondering across 2 years from T1 to T3 (reversed effect model based on two measurement points)

Notes. Time pressure at T1 controlled for in the analyses. Only significant relationships shown. ${ }^{*} p<.05,{ }^{* * *} p<.001$. 


\section{Time 1}

\section{Time 2}

Time 3

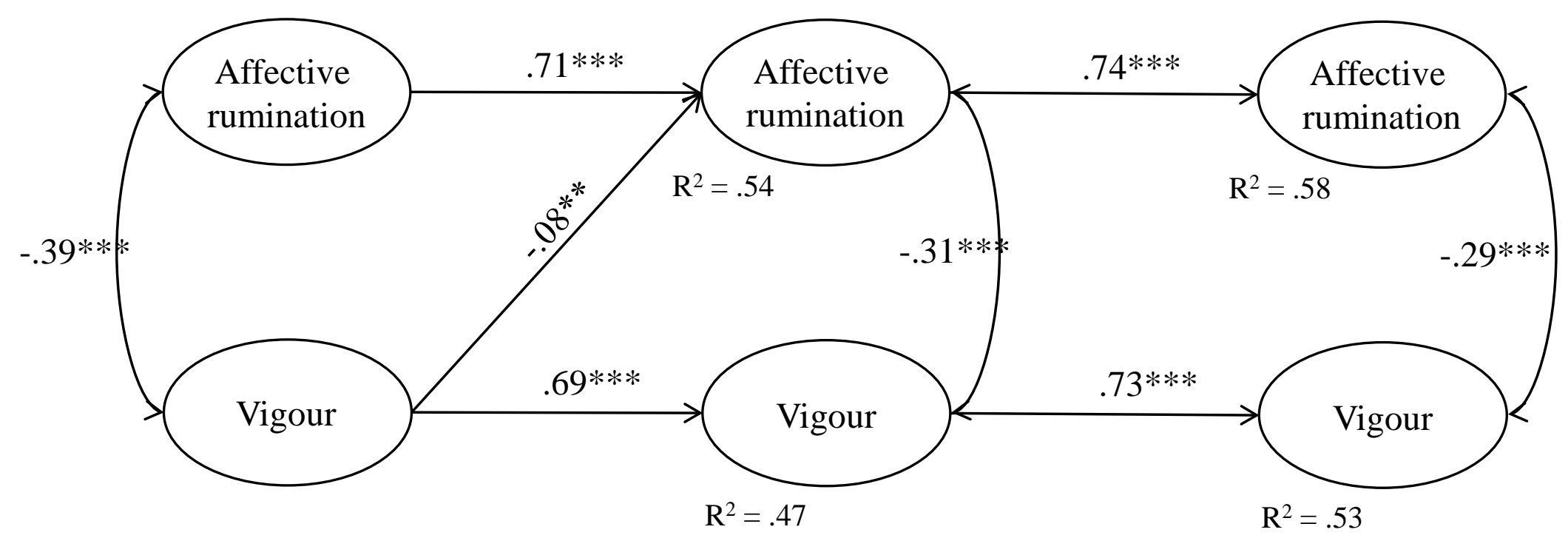

Figure 2a. Vigour predicts affective work-related rumination across 1 year from T1 to T2 (reversed effect model based on three measurements)

Notes. Time pressure at T1 controlled for in the analyses. Only significant relationships shown. ${ }^{* *} p<.01{ }^{* * *} p<.001$. 


\section{Time $1 \quad$ Time 3}

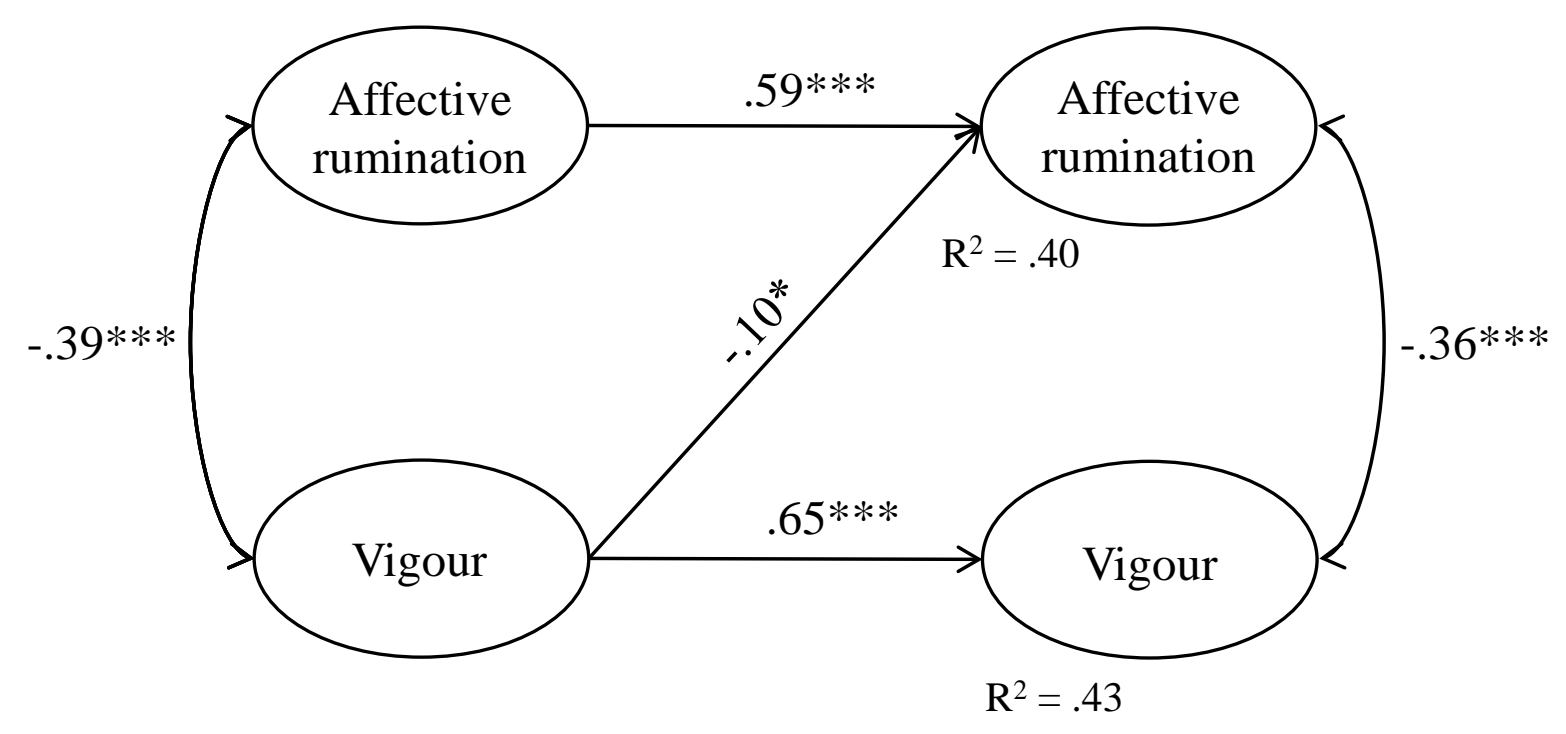

Figure $2 b$. Vigour predicts affective work-related rumination across 2 years from T1 to T3 (reversed effect model based on two measurement points)

Notes. Time pressure at T1 controlled for in the analyses. Only significant relationships shown. ${ }^{*} p<.05,{ }^{* * *} p<.001$. 